\title{
Pón:
}

\section{HABERMAS E A DIFICULDADE DE FUNDAMENTAÇÃO DO PRINCÍPIO (U)}

Andrei Pedro Vanin

Graduando em Filosofia pela Universidade Federal da Fronteira Sul

Adriana Rech

Graduanda em Direito pela Universidade Integrada do Alto Uruguai e das Missões

\section{RESUMO}

Nosso artigo tem por objetivo fazer alguns apontamentos sobre o princípio (U) de Habermas procurando entender como este se relaciona com a ética que nosso autor pretende fundar. Para tanto, no primeiro momento iremos abordar o processo de fundamentação de $(\mathrm{U})$, bem como sua ligação com o princípio (D). Num segundo momento iremos abordar argumentação de Hans Albert, que defende ser impossível qualquer tentativa de fundamentação, e o argumento de Apel que tenta fugir as críticas de Albert. Por fim analisaremos a reconstrução de Habermas do argumento de Apel, para mostrar como a fundamentação de (U) é possível.

Palavras-chave: Princípio (U). Ética. Habermas. Fundamentação. Argumento pragmáticotranscendental.

\begin{abstract}
Our article aims to make some notes about the principle (U) of Habermas trying to understand how it relates to ethics that our author claims to base. Therefore, at first we discuss the process of reasoning (U) and its connection with the principle (D). A second moment we discuss contention Hans Albert, who defends impossible any attempt of reasoning and argument Apel who tries to escape the criticism of Albert. Finally we analyze the reconstruction of Habermas's argument Apel, to show how the reasoning of $(\mathrm{U})$ is possible.
\end{abstract}

Keywords: Principle (U). Ethics. Habermas. Reasoning. Transcendental-pragmatic argument.

\section{Introdução}

Nosso artigo tem por finalidade fazer alguns apontamentos sobre o princípio (U), de Habermas. A partir da análise da obra Consciência Moral e Agir comunicativo (1983), especialmente o terceiro capítulo intitulado Notas programáticas para a fundamentação de uma ética do discurso, pretende-se vislumbrar a ligação que o princípio (U) tem com o princípio (D) e analisar como (U) está relacionado com a ética que Habermas pretende fundar.

Jürgen Habermas, "além de ser um pensador ativo em quase todos os âmbitos da filosofia, tem formulado importantes considerações sobre o estatuto e a lógica das ciências sociais, visando a criação de uma teoria crítica da sociedade”. (PINZANI, 2009, p. 9). Habermas teve várias influências na sua formação, passando por filósofos clássicos, como Hegel e Kant, a sociólogos como Marx, Weber, Parsons e Luhmann. Habermas discutiu 
também com vários filósofos de seu tempo, como Apel, Tungendhat e Rawls e teve, sobretudo a influência da pragmática, na esteira de pensadores como Austin, Strawson, Searle e Rorty. Habermas,

é considerado o membro mais proeminente da segunda geração da Teoria Crítica, isto é, um herdeiro direto de Adorno, Horkheimer e Marcuse; um marxista não ortodoxo que quis dar novos impulsos ao materialismo histórico com a ajuda do pragmatismo norte-americano, com a teoria do desenvolvimento de Piaget e Kohlberg e com a psicanálise de Freud; um filósofo moral e político que desenvolveu uma teoria discursiva da moral e do direito que está entre os empreendimentos filosóficos mais originais da segunda metade do século XX (PINZANI, 2009, p. 9).

A ética do discurso habermasiana, segundo Cenci (2006, p. 15) "começou a ser gestado por Jürgen Habermas e Karl-Otto Apel no período que antecedeu a publicação do texto programático deste último, de 1973, intitulado Das Apriori der Kommunicationsgemeinschaft und die Grundlagen der Ethik". Embora esse projeto tenha começado a ser construído com Apel, no decorrer do projeto Habermas e Apel acabaram tomando rumos distintos, ${ }^{1}$ especialmente no que concerne a fundamentação última ou não da ética.

Habermas, embora se utilize do pensamento de Apel, especialmente nos primeiros escritos, busca uma fundamentação ética que tenha pretensão de validez. ${ }^{2}$ Consoante ao exposto, nosso artigo estrutura-se em dois momentos basilares. No primeiro momento apresenta-se a argumentação de Habermas na tentativa de fundamentar (U) e sua ligação com o princípio (D). Já no segundo momento, abordar-se-á as críticas de Hans Albert a toda tentativa de fundamentação, e o argumento apeliano que tenta refutar a essas objeções levantadas por Albert, bem como, a reestruturação do argumento de Apel por Habermas. Ao final, pretendemos esclarecer como a fundamentação de (U) se dá, demonstrando sua importância para a ética.

\section{O caminho para fundamentar $(U)$}

\footnotetext{
1 Não é nosso objetivo aqui elencar as distinções entre o pensamento de Habermas e Apel. Sobre isso, remetemos nosso leitor a: CENCI, A, A controvérsia entre Habermas e Apel acerca da relação entre moral e razão prática na ética do discurso. C332c. Tese (doutorado) - Universidade Estadual de Campinas, Instituto de Filosofia e Ciências Humanas, Campinas, SP, 2006. Disponível em: <http://ged1.capes.gov.br/CapesProcessos/926961-ARQ/926961_6.PDF>. Acesso em: 10 jun 2012. Cf também: DUTRA, D, Razão e consenso: uma introdução ao pensamento de Habermas. Pelotas, Ed UFPEL, 1993, p. 125130.

${ }^{2}$ HABERMAS, J. Consciência moral e agir comunicativo, Trad. Guido A. de Almeida. Rio de Janeiro, Tempo Brasileiro, 2003. p. 78-79.
} 
Para Habermas, os atos de fala ${ }^{3}$ se dão como uma ação e ao proferirmos uma fala temos pretensão de validade. Cabe então, a pragmática universal "a tarefa de identificar e reconstruir as condições universais do entendimento possível” (CENCI, 1997, p. 16). Habermas classifica em quatro tipos os atos de fala, a saber: 1) atos de fala comunicativos; 2) atos de fala constatativos; 3) atos de fala regulativos; 4) atos de fala representativos. O exame desses atos proporciona as condições "universais da ação comunicativa" (COSTA, 2003, p. 51). Essas condições são pretensões de validade, que nosso autor divide em três tipos, a saber: a) pretensão de verdade - atos constatativos; b) pretensão de correção - atos de fala regulativos; c) pretensão de veracidade - atos de fala representativos ou expressivos. ${ }^{4}$

Nosso autor afirma que "a tentativa de fundamentar a ética sob a forma de uma lógica da argumentação moral só tem perspectiva de sucesso se também pudermos identificar uma pretensão de validez especial, associada a mandamentos e normas". (HABERMAS, 2003, p. 78-79). Consoante ao exposto, nosso autor pretende então demonstrar que é possível fundamentar mandamentos e normas morais.

Para poder justificar a pretensão de validade dos enunciados morais deve-se ter um princípio que permita “distinguir as razões válidas (boas) das inválidas”. (PINZANI, 2009, p. 129). Esse princípio é (U). Como afirma Dutra (1993),

Quando uma norma é problematizada ela tem que apresentar as razões que justifiquem a sua pretensão de validade. Esta tarefa é cumprida por meio de um discurso prático, cujo objetivo é justificar normas de ação. Esse discurso pressupõe contrafaticamente condições de uma situação ideal de fala. E o objetivo de Habermas, na ética, é oferecer um princípio que oriente essa argumentação e fundamentar tal princípio (DUTRA, 1993, p. 105).

Deste modo, "o princípio (U) visa dar conta tanto de permitir - enquanto princípio ponte - o trânsito do particular para o universal no âmbito das argumentações morais quanto de possibilitar - enquanto regra de argumentação moral - o consenso na esfera do discurso

\footnotetext{
${ }^{3}$ A teoria dos atos de fala, especialmente de Austin e Searle, estão intimamente ligados ao que Habermas entende por pragmática universal. "A pragmática universal visa esclarecer as condições que geralmente precisam ser satisfeitas em quaisquer ações comunicativas na linguagem natural". (COSTA, 2003, p. 49). Austin propõe que sempre que dizemos algo com sucesso, realizamos três atos: um ato locucionário - proferir uma sentença com sentido; uma ato ilocucionário - $\mathrm{o}$ ato que realizamos ao dizer algo; e um ato perlocucionário - $\mathrm{o}$ proferimento que "alguém pode realizar pelo fato de haver efetuado um ato ilocucionário" (COSTA, 2003, p. 48) ${ }^{4}$ Cabe notar, com COSTA (2003, p. 52), que as pretensões de verdade estão presentes em todos os atos de fala. Ao proferir um ato de fala constatativo não se tem apenas pretensão de verdade, mas também de sinceridade. "O que faz a diferença entre uma e outra espécie de ato não é, pois, a existência dessa ou daquela pretensão de validade, mas a pretensão de validade que é tematizada, ou seja, enfatizada, posta em relevo. (COSTA, 2003, p. 52).
} 
prático." (CENCI, 2006, p. 99). Para uma norma ter pretensão de validez, ela deve ser problematizada mediante um discurso prático, merecendo assim, o reconhecimento por parte de todos os concernidos:

- que as consequiências e efeitos colaterais, que (previsivelmente) resultarem para a satisfação dos interesses de cada um dos indivíduos do fato de ser ela universalmente seguida, possam ser aceitos por todos os concernidos (e preferidos a todas as consequiências das possibilidades alternativas e conhecidas de regragem) (HABERMAS, 2003, p. 86).

(U), além de assegurar que somente as normas que "exprimam uma vontade universal, possam ser aceitas como válidas," (CENCI, 2006, p. 99) guarda ainda, como em Kant, a impessoalidade e a universalidade e não se esgota "absolutamente na exigência de que as normas morais devem ter a forma de proposições deônticas universais e incondicionais." (HABERMAS, 2003, p. 84). Com efeito, as normas, para serem válidas, tem que merecer, através de (U) o reconhecimento efetivo de todos os concernidos. ${ }^{5}$ É a impessoalidade e a universalidade de (U), que garante as normas serem válidas, ditas como morais. Cenci (2006, p. 100) expõe o papel de ambas:

A imparcialidade refere-se à capacidade de uma norma de ação poder ser reconhecida como válida por qualquer um que exija razões para tal. Ela requer a necessidade de cada um adotar a perspectiva de todos os outros sempre que se tratar da ponderação de interesses. Por sua vez, a universalidade implica a exigência de que as normas contemplem o interesse comum a todos os concernidos e o assentimento universal destes - o seu reconhecimento intersubjetivo.

Habermas aponta que (U), não pode ser aplicado monologicamente, ${ }^{6}$ “"[...] ele só regra as argumentações entre diversos participantes e contém até mesmo a perspectiva para argumentações a serem realmente levantadas a cabo, às quais estão admitidos como participantes todos os concernidos" (HABERMAS, 2003, p. 87). Neste sentido, (U), se

\footnotetext{
${ }^{5}$ Dutra (1993, p. 109) afirma que o julgamento de uma norma "deve vir orientado pela ideia de imparcialidade, universalidade. Só isso pode caracterizar uma norma como moral. $\mathrm{O}$ que determina o caráter moral de uma norma de ação é que tal norma possa oferecer as razões que a fundamentam e ser reconhecida como justa por qualquer um que exigisse tais razões. Age moralmente quem age em acordo com uma norma de ação que possa ser universalizada, isto é, que possa obter o consenso de uma comunidade ideal de comunicação".

${ }^{6}$ Segundo Dutra (1993, p. 109), "(U) exclui uma aplicação monológica de si mesmo, porque o acordo gerado por meio dessa regra deve ser a expressão daquilo que há de comum à vontade de todos. Por isso, nem um só indivíduo pode decidir monologicamente e nem todos podem decidir sem argumentação. É necessário, em todos os casos, o diálogo, o discurso como meio".
} 
diferencia do imperativo categórico de Kant, e do "experimento mental do véu de ignorância de Rawls" (PINZANI, 2009, p. 128). ${ }^{7}$

Devemos ponderar aqui, a distinção entre o princípio (U) e o princípio de uma ética do Discurso (D) ${ }^{8}$. O princípio (U) afirma que as normas só podem ser aceitas como válidas, se forem aceitas por todos os concernidos (HABERMAS, 2003, p. 84). Já o princípio da ética do Discurso (D), afirma que "uma norma só pode pretender validez quando todos os que possam ser concernidos por ela cheguem (ou possam chegar), enquanto participantes de um Discurso prático $^{9}$, a um acordo quanto à validez dessa norma.” (HABERMAS, 2003, p. 86,). O princípio (D) seria a condição de todo o discurso (as condições transcedentais), ao passo que o princípio (U), seria exclusivo da ética, sendo o princípio ponte no discurso prático, possibilitando o consenso. Logo, (D) já pressupõe (U).

Habermas, antes de fundamentar (U), afirma que

Uma ética do Discurso sustenta-se ou cai por terra, portanto, com as duas suposições seguintes: a) que as pretensões de validez normativas tenham um sentido cognitivo e possam ser tratadas como pretensões de verdade; b) que a fundamentação de normas e mandamentos exija a efetuação de um Discurso real e não seja possível monologicamente, sob a forma de uma argumentação hipotética desenvolvida em pensamento. (HABERMAS, 2003, p. 88-89)

\footnotetext{
${ }^{7}$ Não sendo este o escopo de nosso trabalho, porém para manter uma exposição lógica, apenas mencionaremos sucintamente a argumentação de Habermas sobre isso. Kant e Rawls, partem da ideia de que o indivíduo pode por si só, "fundamentar monologicamente as normas morais fundamentais. Habermas, ao contrário de Kant e Rawls, é da opinião que essa tarefa só pode ser cumprida cooperativamente. Uma argumentação moral serve a consertar o acordo sobre normas e regras de ação, se este faltar.” (PINZANI, 2009, p. 128).

Habermas, citando Carth, em seu trabalho Kritik der Verständigungsverhältnisse, afirma que o Imperativo Categórico Kantiano, precisa ser reformulado. "Ao invés de prescrever a todos os demais como válida uma máxima que eu quero que seja uma lei universal, tenho que apresentar minha máxima a todos os demais para o exame discursivo de sua pretensão de universalidade. O peso desloca-se daquilo que cada (indivíduo) pode querer sem contradição como lei universal para aquilo que todos querem de comum acordo reconhecer como norma universal". (CARTH, Kritik der Verständigungsverhältnisse, Frankfurt, 1980, p. 371. In: HABERMAS, Consciência moral e agir comunicativo, 2003, p. 88. Passemos ao largo da problemática questão introduzida por Habermas ao tratar de "interesse", no que tange ao consenso cooperativo das normas morais. Para tanto Cf: PINZANI, A, Habermas, Porto Alegre, Artmed, 2009, p. 128-129.

${ }^{8}$ Segundo Delamar Dutra, tradutor do artigo de BERTEN, A, Habermas crítico de Rawls. A posição original do ponto de vista da pragmática universal. In: Filosofia, Lógica e Existência. Org: Luiz Carlos Bombassaro, Jayme Paviani. Caxias do sul, EDUCS, 1997, p. 28 a melhor tradução para o termo alemão Diskursethik seria "por ética discursiva, isto porque o adjetivo discursiva qualifica a ética como tal. A outra opção em português seria ética do discurso. O problema desta tradução é que o discurso não significa um qualitativo de ética, mas que podemos achar uma ética do discurso, assim como podemos achar uma ética da política ou uma ética de mercado. Cabe observar que a tradução francesa utiliza o termo éthique de la discussion." Sabidos dessa ponderação, mas por ser mais corrente o uso de ética do discurso, iremos, sempre que nos referirmos a "ética discursiva" usar o termo ética do discurso.

${ }^{9}$ Grifos do autor.
} 
Até o momento Habermas apenas introduziu o princípio (U), não o fundamentando strictu sensu. Ele aponta para a dificuldade de fundamentar tal princípio. Para tanto, nosso segundo momento deste artigo, tem por objetivo mostrar quais são as dificuldades de fundamentação última encontradas por Habermas, apontando a solução de Apel para superar ao problema de fundamentação e por fim, apresentar a argumentação de Habermas para conseguir - apoiado no argumento de Apel - fundamentar sua ética. Passemos ao nosso segundo ponto.

3. As dificuldades de fundamentação: Albert, Apel e o argumento pragmáticotranscendental de Habermas

A fundamentação de (D) de Apel e Habermas, recebe as objeções de Hans Albert. Habermas formula o princípio (U) posteriormente a tentativa de fundamentação de Apel. Embora Habermas seja um cognitivista, ele não pretende uma fundamentação última, caso que Apel defende. Para entendermos como Habermas, na esteira de Apel, foge a essas objeções, iremos analisar brevemente os argumentos de Albert, contra a fundamentação, na obra Tratado da razão Crítica. Num segundo momento, iremos analisar a solução apresentada por Karl-Otto Apel, para contrapor-se aos problemas de fundamentação apresentados por Albert. Por fim, iremos abordar - mesmo que sucintamente - como Habermas contradiz Albert, apoiado em Apel e ao mesmo tempo, modificando a argumentação de Apel em favor de uma pragmática universal sem pretensões de fundamentação última.

Para Albert, que concebe a linguagem em um sentido lógico semântico, a fundamentação só seria possível através de deduções lógicas, que são “[...] uma sequência de enunciados, de premissa e conclusões, entre os quais existem determinadas relações lógicas, isto é: uma conclusão é deduzível das premissas em questão com a ajuda de regras lógicas." (ALBERT, 1976, p. 25). Dutra (1993, p. 111) aponta que, "a fundamentação do conhecimento acontece através da indicação de fundamentos seguros e, portanto, indubitáveis, a que se chega através de deduções".

Não obstante, segundo Albert "através de deduções lógicas nunca se pode obter um conteúdo" (ALBERT, 1976, p. 25), já que a conclusão, não dá um saber novo, mas apenas sintetiza o que já estava posto nas premissas. Um argumento dedutivo válido, não garante necessariamente que o conteúdo das premissas e da conclusão sejam válidos. Com efeito, quando se busca um conhecimento indubitável, "se cobra também uma fundamentação para a 
base de proposições a partir da qual outras proposições são deduzidas" (SANTOS, 2007, p. 82). Segundo Albert, ao tentar fundamentar a base das proposições, somos levados ao Trilema de Münchhausen, que constitui-se de três alternativas: ${ }^{10}$ um regresso ao infinito; um círculo lógico; ou uma parada arbitrária.

Albert, não defendendo uma fundamentação universal e pragmática da linguagem, propõe o princípio da verificação crítica, que seria como expõe Dutra (1993, p. 112), um levantamento de dados, uma espécie de ensaio e erro, até encontrar-se a verdade ${ }^{11}$. Ao tratar da ética, Albert também defende a impossibilidade de fundamentação, já que levaria ao Trilema de Münchhausen e por sua vez, ao tentar encontrar princípios supremos da ética, isso levaria a uma "dogmatização de princípios tradicionais de valoração" (ALBERT, 1976, p. 77). A saída para a não dogmatização seria o princípio da verificação crítica, que possibilitaria o julgamento crítico de qualquer posição a ser tomada. (SANTOS, 2007, p. 83).

Dutra (1993) aponta que a conclusão de Albert, é "que os enunciados éticos são sempre hipotéticos, mas que podem ser sempre submetidos ao princípio do criticismo. O criticismo leva a "fundamentar" os enunciados éticos na consciência dos homens e em sua forma de vida, mas nunca a dogmatizá-los como princípios abstratos sem significação existencial" (DUTRA, 1993, p. 112).

Habermas, não se filia e diz ser problemática a tese de Albert, pois o valor posicional "só aparece com a pressuposição de um conceito semântico de fundamentação, que se orienta pela relação dedutiva entre proposições e que se apóia unicamente no conceito da inferência lógica". $^{12}$ (HABERMAS, 2003, p. 101). Deste modo, Habermas irá se apoiar na argumentação de Apel, que "introduz contra Albert a ideia de uma fundamentação não dedutiva e transcendental das normas éticas fundamentais que se serve de meios pragmáticolinguísticos e utiliza o conceito de contradição performativa" (PINZANI, 2009, p. 130).

Apel pensa que o criticismo (ou princípio de verificação crítica) não resolve o problema na tentativa de fugir da fundamentação última. Para Apel

\footnotetext{
10 1) um regresso infinito, que parece resultar da necessidade de sempre, e cada vez mais, voltar atrás na busca de fundamentos, mas que na prática não é passível de realização e não proporciona nenhuma base segura; 2) um círculo lógico na dedução, que resulta da retomada, no processo de fundamentação, de enunciados que já surgiram anteriormente como carentes de fundamentação, e o qual, por ser logicamente falho, conduz do mesmo modo a nenhuma base segura, e finalmente, 3) uma interrupção do procedimento em um determinado ponto, o qual, ainda que pareça realizável em princípio, nos envolveria numa suspensão arbitrária do princípio da fundamentação suficiente (ALBERT, 1976, p. 26-27).

${ }^{11}$ Cf: ALBERT, 1976, p. 52s.

${ }^{12}$ Grifos do autor.
} 
[...] o racionalismo crítico não consegue explicar nem manter o sentido de sua posição teórica sem eliminar definitivamente determinados pressupostos subjacentes aos procedimentos de falseamento e crítica, quais sejam, as pressuposições pragmático-transcendentais do próprio jogo de linguagem utilizadas na crítica. (CENCI, 2006, p. 38)

Apel na esteira de Wittgenstein - dos jogos de linguagem - e de Searle e Austin - dos atos de fala - afirma não ser mais possível utilizar o conhecimento sem pressupor o "contexto de interpretação e coerência lógica"13 que se está utilizando um discurso linguístico. Assim, o próprio discurso pressupõe regras lógicas a serem seguidas, quando se quer ser entendido. Apel faz uso aqui do que já Aristóteles, no livro IV da Metafísica, formula como o princípio de não contradição. Este princípio, afirma o filósofo, não pode ser demonstrado, mas se queremos ser compreendidos ou falar algo com sentido, devemos utilizá-lo inevitavelmente e assim somos levados a admitir tal princípio. ${ }^{14}$ Embora a argumentação de Apel se assemelhe a de Aristóteles, o conteúdo se diferencia. ${ }^{15}$

Segundo Apel, Albert, ao pressupor "que tudo é dubitável, deve pressupor um "a priori” que seja indubitável, a saber, a argumentação onde se processa a própria crítica. Este “a priori” é uma evidência indubitável” (DUTRA, 1993, p. 114). Apel afirma que o cético ao defender que "tudo é dubitável", tem de admitir que tal enunciado também o é, caindo assim em autocontradição. Dutra (1993, p. 114) aponta ainda, que essa autocontradição é o mesmo paradoxo do mentiroso. Quando o mentiroso afirma "todos são mentirosos", este suprime a própria pretensão de validade.

Apel defenderá a existência de enunciados que não podem ser postos sob o princípio da verificação crítica. Tais enunciados são os autenticamente filosóficos, que guardam a característica de serem universais e auto-referentes. ${ }^{16}$ A racionalidade filosófica, "trata-se de uma fundamentação filosófica última não-dedutiva, que recorre a uma evidência que não pode ser questionada sem autocontradição perfomativa [...]" (DUTRA, 1993, p. 114). ${ }^{17}$ Essas evidências performativas segundo Apel, "não podem ser colocadas em questão pela crítica

\footnotetext{
${ }^{13}$ Cf: CENCI, 2006, p. 40.

${ }^{14}$ Cf: ARISTÓTELES, Metafísica, IV, 3 - 4, 1006 a -1009 a. Trad Marcelo Perine, 2 ed, São Paulo, Loyola, 2002 , p. 145-163. Aristóteles formula o princípio de não contradição, mas só pode "demonstrá-lo" por via da refutação. Sobre isso Cf: DUTRA, Demonstrar por refutação, In: Filosofia, Lógica e Existência. Org: Luiz Carlos Bombassaro, Jayme Paviani. Caxias do sul, EDUCS, 1997, p. 48-66.

${ }^{15}$ Não é nosso objetivo aqui, nem teríamos a precisão conceitual necessária para expor tais diferenças. Para tanto, Cf: Cenci, 2006, p. 40-42. Quanto a uma demonstração mais precisa do princípio que Habermas utiliza e suas diferenças a Aristóteles, Cf: DUTRA, Demonstrar por refutação, In: Filosofia, Lógica e Existência. Org: Luiz Carlos Bombassaro, Jayme Paviani. Caxias do sul, EDUCS, 1997, p. 48-66.

${ }^{16}$ Cf: Dutra, 1993, p. 114. Cf também: Cenci, 2006, p. 43.

${ }^{17}$ Grifos do autor.
} 
sem se contradizer elas mesmas, sem ser fundamentadas dedutivamente sem pressupor elas mesmas [...] Essas evidências últimas não podem nem ser contestadas sem autocontradição, nem ser fundamentadas sem petitio principii” (APEL, Apud DUTRA, 1993, p. 114-115). ${ }^{18}$

Com efeito, quando se quer argumentar sobre algo deve-se pressupor regras lógicas que permitam ao discurso ter sentido. Apel, com essa tese, pretende mostrar que inevitavelmente quem participa de um discurso, aceita determinadas regras que ficam livres de qualquer crítica, por serem essenciais (pressupostos) em qualquer argumentação. ${ }^{19}$ Deste modo, como aponta Pinzani (2009, p. 131) "até o cético que não queira entrar em uma argumentação moral reconhece tais princípios, uma vez que sua crítica é concebida, de forma geral, em termos argumentativos."

Habermas, valendo-se da argumentação de Apel, contra a impossibilidade de fundamentação, irá propor o argumento pragmático transcendental para fundamentar (U). Habermas, afirma que a "concepção dedutivista da fundamentação é, manifestamente, seletiva demais para a exposição das relações pragmáticas entre atos de fala argumentativos: os princípios de indução e da universalização só são introduzidos como regras da argumentação para lançar uma ponte sobre o hiato lógico nas relações não-dedutivas" (HABERMAS, 2003, p. 101). Assim, os princípios de indução e universalização funcionam como princípios pontes. No caso de $(\mathrm{U})$, esses princípios fazem a passagem dos interesses individuais para os universais (Cenci, 2006, p. 103). Habermas, certificando-se da possibilidade de uma fundamentação da moral, ${ }^{20}$ irá reformular o argumento de Apel, para fundamentar (U) e buscar, através de um modelo mais fraco de fundamentação pragmático-transcendental, uma fundamentação sem pretensões definitivas (últimas). Vejamos como isso procede.

Habermas parte da ideia de que é necessário indicar as condições que o argumento transcendental possa ser aplicado. Para ele só pode-se denominar argumentos transcendentais aqueles que "se dirigem a Discursos ou competências correspondentes que sejam tão universais que não possam ser substituídos por equivalentes funcionais [...]" (HABERMAS, 2003, p. 106). Assim, Habermas, para fundamentar (U), irá mostrar que o papel do argumento

\footnotetext{
${ }^{18}$ Grifos do autor.

${ }^{19}$ Corrobora Dutra (1993, p. 115), que “[...] as pretensões de validade são uma condição última e inegável da argumentação e qualquer um que queira participar seriamente de uma argumentação não pode negá-las, pois elas constituem-se numa evidência performativa do participante da argumentação".

${ }^{20}$ Apel, "não se satisfaz em aplicar o conceito de contradição performativa apenas a atos de fala e a argumentos, mas dirige-o ao discurso argumentativo como um todo. Ele não limita a análise pressuposicional apenas à esfera das argumentações morais, mas a aplica "às condições da possibilidade do discurso argumentativo em geral". Dessa forma, ao entrar numa argumentação todo sujeito capaz de fala e ação tem de aceitar pressupostos com conteúdo normativo, os quais são inevitáveis.”(CENCI, 2006, p. 104).
} 
pragmático-transcendental tem que assumir, é explicitar que (U) já está implicado na argumentação. Isso poderá ser demonstrado se "- todo aquele que aceita as pressuposições comunicacionais universais e necessárias do discurso argumentativo e que sabe o que quer dizer justificar uma norma de ação tem que presumir implicitamente a validade do princípio da universalização" (HABERMAS, 2003, p. 109-110).

Habermas quer mostrar assim que sempre que se entra em um discurso argumentativo, tem-se que fazer pressuposições no qual o conteúdo serve como regra de discurso, pois "todos os que empreendem seriamente a tentativa de resgatar discursivamente pretensões de validez normativa aceitam intuitivamente condições de procedimento que equivalem a um reconhecimento implícito de 'U'.' (HABERMAS, 2003, p. 115-116). Essas condições, assim como na argumentação de Apel, não podem ser negadas, já que se incorreria em contradição performativa.

(U) será demonstrado então, quando as condições de procedimento puderem reger uma argumentação "vista como um processo comunicativo que visa um consenso racionalmente motivado e está imunizado contra coação e desigualdade" (PINZANI, 2009, p. 131). Para esse plano, tem-se - como Alexy propôs - as seguintes regras:

(3.1) É lícito a todo sujeito capaz de falar e agir participar de Discursos. (3.2) a. É lícito a qualquer um problematizar qualquer asserção. b. É lícito a qualquer um introduzir qualquer asserção no discurso. c. É lícito a qualquer um manifestar suas atitudes, desejos e necessidades. (3.3) Não é lícito impedir falante algum, por uma coerção exercida dentro ou fora do Discurso, de valer-se de seus direitos estabelecidos em (3.1) e (3.2) (HABERMAS, 2003, p. 112).

Aceitando essas premissas, como aponta Pinzani (2009, p. 132) “dispomos de premissas suficientemente fortes para a dedução de (U)", pois essas regras são pressuposições inevitáveis, pois quando quisermos negá-las cairemos em contradição performativa. Não podemos argumentar com força (sentido) se não seguirmos essas regras, nem será possível fundamentar (U). Com efeito,

Se todos os que entram em argumentações têm que fazer, entre outras coisas, pressuposições cujo conteúdo pode ser apresentado sob a forma de regras do Discurso (3.1) a (3.3); e se, além disso, compreendemos as normas justificadas como regrando matérias sociais no interesse comum de todas as pessoas possivelmente concernidas, então todos os que empreendem seriamente a tentativa de resgatar discursivamente pretensões de validez normativas aceitam intuitivamente condições de procedimento que equivalem a um reconhecimento implícito de 'U' (HABERMAS, 2003, p, 115-116). 
O princípio (U) pode se fundamentado "mediante uma derivação pragmáticotranscendental que toma como ponto de partida para tal determinadas pressuposições argumentativas." (CENCI, 2006, p. 116). Uma norma controversa, só pode ser fundamentada "se as conseqüências e efeitos colaterais, que previsivelmente resultam de uma obediência geral da regra controversa para a satisfação dos interesses de cada indivíduo, podem ser aceitos sem coação por todos" (HABERMAS, 2003, p. 116). Deste modo - mostrado que o princípio de universalização pode ser fundamentado através da derivação pragmáticotranscendental - "a ética do Discurso ela própria pode ser reduzida ao princípio parcimonioso ' $\mathrm{D}$ ' segundo o qual: - só podem reclamar validez as normas que encontrem (ou possam encontrar) o assentimento de todos os concernidos enquanto participantes de um Discurso prático” (HABERMAS, 2003, p. 116).

Nosso autor distingue (U), a) de princípios ou normas conteudísticas; b) do conteúdo normativo das pressuposições da argumentação; c) do princípio (D), enquanto princípio da ética do Discurso. ${ }^{21} \mathrm{O}$ princípio (U) é o princípio ponte que na moral desempenha uma papel equivalente da indução na ciência empírica. Pinzani (2009, p. 132) aponta que:

(U) não corresponde, então, a um princípio com conteúdo ético, assim como (D) não corresponde ao conteúdo normativo das pressuposições da argumentação do tipo 3.1, 3.2 e 3.3. Ele se limita a dizer quando uma norma é capaz de obter consenso; ele afirma, com isso, quais são as condições para tal consenso. (D), ao contrário, afirma que uma norma deve obter o consenso de todos os concernidos; ele possui, portanto, caráter normativo.

Apontado o processo de fundamentação de (U), poderíamos, seguindo a reconstrução de Pinzani (2009), apontar os quatro passos para a fundamentação da ética do discurso. O primeiro passo consiste na "apresentação de (U) como regra da argumentação"; o segundo seria a "identificação de pressuposições pragmáticas da argumentação que sejam inevitáveis e possuam conteúdo normativo; ao passo que a terceira possibilitaria a "explicitação do conteúdo normativo dessas pressuposições na forma de regras do discurso; e por fim a “demonstração do fato de que entre esses três passos subsiste uma relação de implicação material (não simplesmente lógica), no que diz respeito à justificação de normas”. (PINZANI, 2009, p. 132).

\section{Considerações finais}

\footnotetext{
${ }^{21}$ Cf: HABERMAS, 2003, p. 116.
} 
O trabalho empreendido até aqui nos permitiu esclarecer alguns dos pontos centrais da ética de Habermas. Para tanto num primeiro momento, apresentamos a argumentação de Habermas na tentativa de fundamentar (U) e sua ligação com o princípio (D). Tratamos também, mesmo que sucintamente, o que nosso autor entende por pragmática universal e como seu princípio de universalização se distancia de Kant e Rawls.

Já no segundo momento, procuramos identificar as principais dificuldades que Habermas encontrou para fundamentar (U). Para tanto, trabalhamos com as críticas que Hans Albert levanta contra toda a tentativa de fundamentação, bem como, a argumentação de Apel, que foge a essas objeções e cria as condições - das quais Habermas se vale - para fundamentar (U). Podemos concluir afirmando que o principio (U), como regra de argumentação moral, deve satisfazer a todos os que estão no discurso, bem como, os que serão implicados pelas normas. Assim, as normas só serão consideradas válidas se puderem ser reconhecidas por todos, manifestando uma vontade universal.

\section{Referências bibliográficas}

ALBERT, Halbert. Tratado da razão crítica. Rio de Janeiro: Tempo Brasileiro, 1976. ARISTÓTELES, Metafísica. Trad Marcelo Perine, 2 ed, São Paulo: Loyola, 2002. BOMBASSARO, L.C; PAVIANI, J. Filosofia, Lógica e Existência. Caxias do sul: EDUCS, 1997.

CENCI, A, A controvérsia entre Habermas e Apel acerca da relação entre moral e razão prática na ética do discurso. C332c. Tese (doutorado) - Universidade Estadual de Campinas, Instituto de Filosofia e Ciências Humanas, Campinas, SP, 2006. Disponível em: <http://ged1.capes.gov.br/CapesProcessos/926961-ARQ/926961_6.PDF>. Acesso em: 10 jun 2012 .

COSTA, C.F, Filosofia da linguagem. $2^{\mathrm{a}}$ ed. Rio de janeiro: Jorge Zahar Ed, 2003.

DUTRA, D. Razão e consenso: uma introdução ao pensamento de Habermas. Pelotas: Ed UFPEL, 1993

HABERMAS, J. Consciência moral e agir comunicativo, Trad. Guido A. de Almeida. Rio de Janeiro: Tempo Brasileiro, 2003.

PINZANI, A, Habermas, Porto Alegre: Artmed, 2009.

SANTOS, F.E, (2007) A fundamentação da moral em Jürgen Habermas, 144 f. Dissertação (mestrado) - Universidade Federal de Minas Gerais, Faculdade de Filosofia e Ciências Humanas, Curso de Pós-Graduação em Filosofia, Belo Horizonte, 2007. Disponível em: $<$ http://www.bibliotecadigital.ufmg.br/dspace/bitstream/1843/ARBZ-

7FYNVR/1/disserta_o_fabio_eul_lio_dos_santos.pdf> Acesso em: 16 jul 2012. 